\title{
Kajian anggaran biaya K3 proyek peningkatan ruas jalan Bagbagan-Mekarasih, Sukabumi
}

\author{
Paikun a,1, ${ }^{*}$, Muhamad Rizal Jaelani a,2, Arif Yusron Afifi b,3, Nadhya Susilo Nugroho b,4, Raflis c,5 \\ ${ }^{a}$ Program Studi Teknik Sipil Universitas Nusa Putra, Sukabumi, Indonesia \\ ${ }^{b}$ IPB University, Bogor, Indonesia \\ ${ }^{\mathrm{C}}$ Departement of Civil Engineering, Faculty of Civil Engineering and Planning, Trisakti University, Jakarta 11440, Indonesia \\ ${ }^{1}$ paikun@nusaputra.ac.id*; ${ }^{2}$ muhamad.rizal_ts18@nusaputra.ac.id; ${ }^{3}$ arifyusron@apps.ipb.ac.id; ${ }^{4}$ nadhyasn20nugroho@apps.ipb.ac.id \\ ${ }^{5}$ Raflis@trisakti.ac.id \\ * Corresponding Author
}

Received 01 July 2021; revised 15 July 2021; accepted 18 july 2011

\section{ABSTRAK}

Maraknya kasus kecelakaan pada proyek konstruksi, mengingatkan bahwa aspek K3 butuh perhatian dari para kontraktor. Padahal, K3 adalah aspek terpenting dalam penyelenggaraan konstruksi. Upaya meminimalisir kecelakaan bisa dengan melaksanakan Sistem Manajemen Keselamatan dan Kesehatan Kerja (SMK3). Penyedia jasa konstruksi harus menyediakan biaya untuk keperluan K3. Karena estimasi biaya sangat berpengaruh dan menjadi tolak ukur dalam mengevaluasi keberhasilan suatu proyek konstruksi. Penelitian ini bertujuan untuk mengetahui perbandingan biaya K3 antara peraturan dan fakta lapangan. Observasi dilapangan untuk mendapat data biaya K3 secara langsung, kemudian menyusun daftar risiko yang terjadi, menilai risiko, mitigasi risiko. Selanjutnya melakukan perbandingan harga untuk keperluan K3 antara RAB dengan harga keperluan K3 menurut Surat Edaran Nomor 11/SE/M/2019 dan menghitung biaya persentase terhadap kontrak. Hasil penelitian teridentifikasi 27 risiko kecelakaan kerja dengan 5 kategori rendah dan 22 kategori sedang. Untuk biaya K3 yang diperlukan berdasarkan harga satuan lapangan dan RAB adalah sebesar Rp. 16.700.000,00 sedangkan biaya berdasarkan Surat Edaran Nomor 11/SE/M/2019 adalah Rp. 146.710.000,00. Biaya K3 dilapangan lebih kecil dengan selisih 0,81\% atau sebesar Rp. $130.010 .000,00$, hal ini disebabkan karena tidak tercantumnya kebutuhan K3 seperti APD baik untuk keperluan pekerja dan lain sebagainya sesuai dengan peraturan yang berlaku. Penyedia jasa konstruksi seharusnya menyediakan biaya untuk keperluan K3 yang diambil dari total biaya proyek meskipun masuk kategori biaya umum dan tidak spesifik tercantum dalam kontrak.

Study of the K3 budget for the Bagbagan-Mekarasih road improvement project, Sukabumi

ABSTRACT

The number of cases of accidents in construction projects reminds us that the K3 aspect needs attention from contractors. In fact, $\mathrm{K} 3$ is the most important aspect in the implementation of construction. Efforts to minimize accidents can be done by implementing the Occupational Health and Safety Management System (SMK3). Construction service providers must provide costs for K3 purposes. Because cost estimation is very influential and becomes a benchmark in evaluating the success of a construction project. This study aims to determine the comparison of $\mathrm{K} 3$ costs between regulations and field facts. Observation in the field to obtain data on K3 costs directly, then compiling a list of risks that occur, assessing risks, and mitigating risks. Next, compare the price for $K 3$ needs between RAB and the price for K3 needs according to Circular Number 11/SE/M/2019 and calculate the percentage fee for the contract. The results of the study identified 27 occupational accident risks with 5 low and 22 medium categories. The required $K 3$ costs based on the field unit price and $R A B$ is $R p .16,700,000.00$ while the fee based on Circular Letter Number 11/SE/M/2019 is Rp. 146,710,000.00. K3 costs in the field are smaller with a difference of $0.81 \%$ or Rp. 130,010,000.00, this is due to the absence of K3 needs such as PPE both for workers' needs and so on by applicable regulations. Construction service providers should provide costs for K3 purposes which are taken from the total project costs even though they are included in the general and non-specific cost categories listed in the contract.

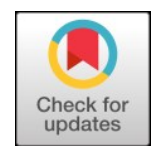

\section{KATA KUNCI}

Identifikasi risiko

Penilaian risiko

Biaya K3

Mitigasi risiko

Kecelakaan Proyek

\section{KEYWORDS}

Risk identification Risk assessment K3 Cost

Risk mitigation

Project Accident 


\section{Pendahuluan}

Maraknya kasus kecelakaan pada proyek konstruksi, mengingatkan bahwa aspek K3 butuh perhatian dari para kontraktor [1]. Keselamatan dan Kesehatan kerja (K3) adalah aspek terpenting dalam penyelenggaraan konstruksi [2]. Keselamatan konstruksi adalah setiap kegiatan rekayasa yang bertujuan membantu pekerjaan konstruksi untuk memenuhi standarisasi K3 dalam menjamin keselamatan dan kesehatan manusia, keselamatan publik dan lingkungan [3]. Penyedia jasa konstruksi terus berupaya mengurangi kecelakaan dengan memperkenalkan sistem manajemen kesehatan dan keselamatan kerja (SMK3). Selain itu, dari sudut pandang pemilik proyek, perkiraan biaya sangat penting dan menjadi salah satu kriteria penting dalam mengevaluasi keberhasilan proyek [4]. Namun, peraturan tidak secara jelas mengatur biaya K3, dan menjadi kendala pelaksanaan K3 selama ini [5]. Seperti yang didasarkan pada Peraturan Menteri Pekerjaan Umum dan Perumahan Rakyat Republik Indonesia Nomor 21/PRT/M/2019 Tentang Pedoman Sistem Manajemen Keselamatan Konstruksi pada Bab 3, Pasal 27 dan Pasal 28, mengatur mengenai biaya pelaksanaan sistem manajemen keselamatan konstruksi [6]. Penyedia jasa konstruksi harus mengkompensasi biaya target K3 dari total biaya proyek, meskipun biaya tersebut termasuk dalam kategori biaya umum dan tidak khusus yang tercantum dalam kontrak [7].

Penelitian ini bertujuan untuk menganalisis, mengidentifikasi bahaya yang muncul dan melakukan perbandingan biaya K3 dengan studi kasus proyek perbaikan jalan Bagbagan-Mekarassih di wilayah Sukabumi. Ruang lingkup penelitian adalah estimasi biaya K3 yang diperlukan sesuai dengan Peraturan Menteri Pekerjaan Umum dan Perumahan Rakyat Republik Indonesia Nomor 21/PRT/M/2019 Tentang Pedoman Sistem Manajemen Keselamatan Konstruksi. Sehingga ini diharapkan dapat menambah tolak ukur terkait perhitungan perkiraan biaya K3 di beberapa bidang konstruksi, terutama dalam pelaksanaan proyek peningkatan/pelebaran jalan raya. Penelitian ini diharapkan dapat berkonstribusi dalam pelaksanaan SMK3 pada proyek konstruksi untuk menjalankan K3 dengan baik agar tidak terjadi kecelakaan akibat konstruksi. Penelitian ini menjadi tolak ukur bagi penyelenggara proyek konstruksi untuk mempersiapkan biaya konstruksi sesuai kebuthan serta mengacu pada ketentuan peraturan dan perundangan yang berlaku, dan menjadi gambaran bagi penyedia jasa konstruksi untuk menerapkan K3 secara optimal dengan memperhatikan potensi bahaya dan menanggulanginya sesuai dengan anggaran biaya yang disediakan.

\section{Metode}

Objek penelitian bertempat di daerah kecamatan simpanan kabupaten Sukabumi tepatnya di ruas jalan Bagbagan - Mekarasih yang memiliki Panjang jalan 8,10 Km dan lebar $4 \mathrm{~m}$ secara faktual, proyek peningkatan jalan di wilayah Kabupaten Sukabumi hampir $80 \%$ berupa jalan beton semen portland/perkerasan kaku atau rigid pavement design. Beberapa pertimbangan antara lain; (1) Kondisi geografis wilayah Kabupaten Sukabumi; (2) Lintas Harian Rata-rata (LHR) (padat); (3) Beban muatan kendaraan yang melintas tinggi (truk dan kontainer); (4) Tipikal drainase flat. Lokasi peta dari kecamatan simpenan bisa dilihat di Gambar 1.

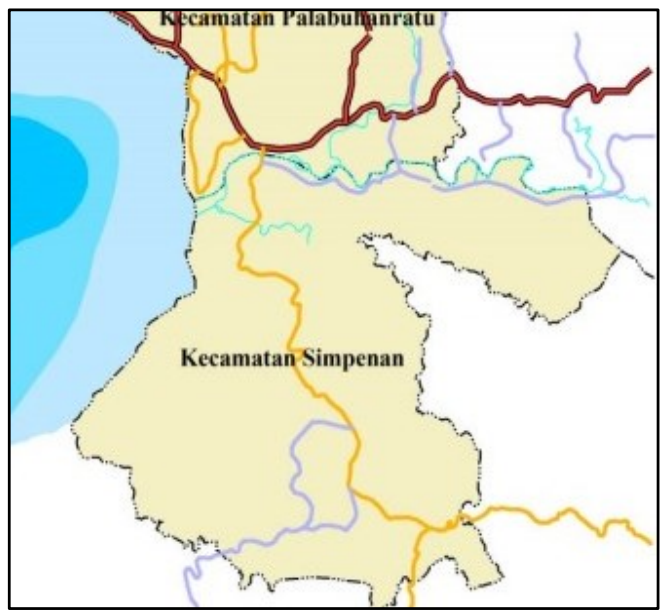

Gambar 1. Lokasi Kec. Simpenan, Sukabumi 
Penelitian dilaksanakan dalam bentuk survey dan wawancara untuk memperoleh data-data yang diperlukan dalam analisis [8]. Survey dilakukan untuk mencari rincian harga peralatan K3 dan wawancara dilakukan untuk menentukan risiko-risiko yang terjadi selama masa pelaksanaan proyek. Wawancara dilakukan dengan personil K3 proyek. Analisis data menggunakan bantuan Microsoft Excel dengan memasukkan semua komponen yang akan dianalisis. Sumber data yang digunakan untuk penelitian ada 2 (dua) jenis data yaitu data primer dan data sekunder. Data primer dalam penelitian ini diperoleh dari survey harga di toko yang berada dekat dengan lokasi proyek juga hasil wawancara dengan personil K3 proyek serta pengamatan langsung di lapangan. Sedangkan data sekunder yang digunakan yaitu studi terdahulu, Rencana Anggaran Biaya (RAB) proyek, daftar analisa pekerjaan dan time schedule . Dengan tahapan penelitian seperti dijelaskan pada Gambar 2.

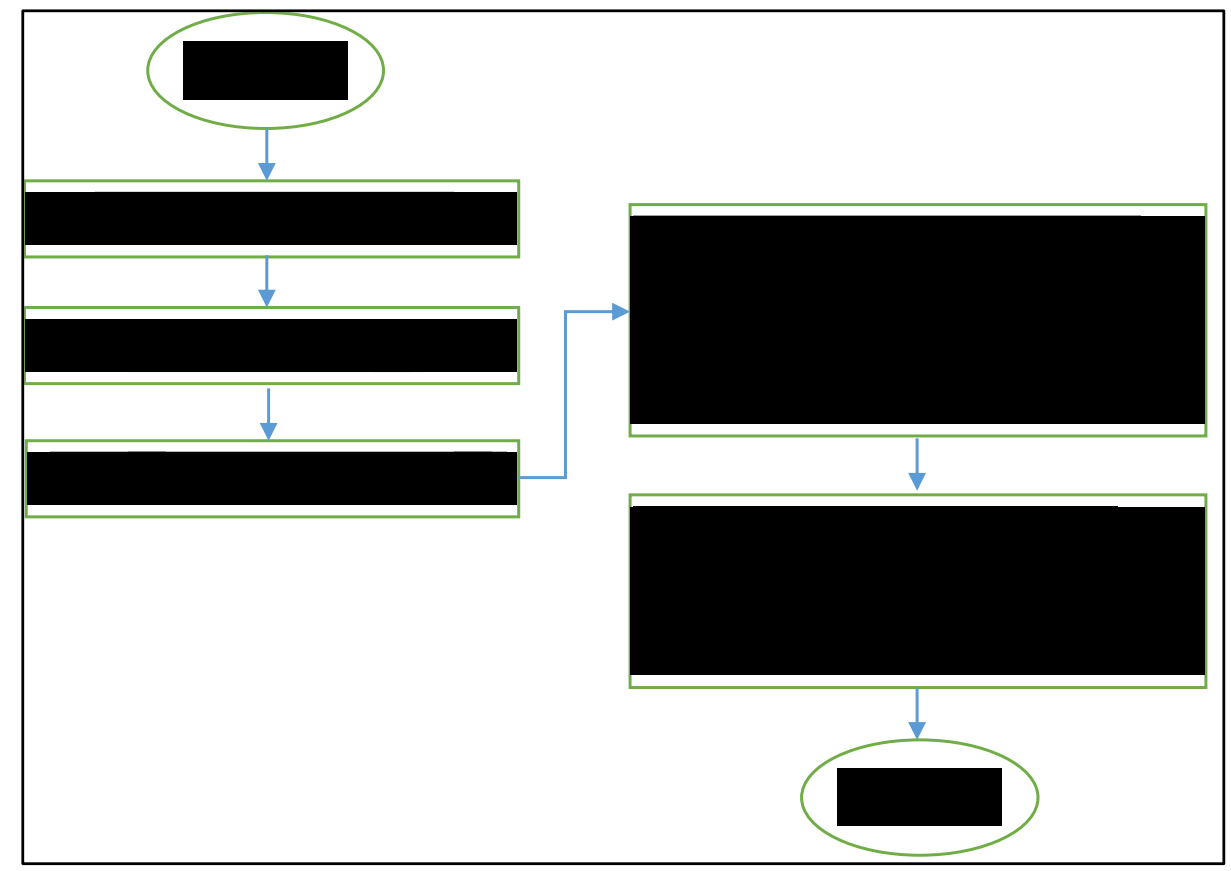

Gambar 2. Tahapan Penelitian

\section{Hasil dan Pembahasan}

\subsection{Identifikasi Bahaya, Penilaian dan Pengendalian Risiko}

Identifikasi terhadap risiko tentang keselamatan dan kesehatan kerja selama pelaksanaan proyek dilakukan melalui wawancara dengan personil K3 proyek [9]. Selain itu, dilakukan pengamatan lapangan untuk melihat risiko- risiko yang mungkin terjadi akibat pelaksanaan pekerjaan [10]. Sedangkan untuk peniliaian risiko adalah kegiatan yang menguraikan suatu risiko dengan cara menentukan besarnya kemungkinan/probability dan tingkat keparahan dari akibat/consequences suatu risiko bahaya [11]. Kemudian dilakukan tindakan mitigasi pengendalian terhadap risiko guna meminimalisir ppotensi kecelakaan yang terjadi [12]. Pengendalian risiko diperoleh melalui wawancara dengan personil K3 termasuk inspeksi yang meliputi; tempat kerja; peralatan kerja; cara kerja; alat pelindung diri; ramburambu; lingkungan kerja konstruksi sesuai RK3K. Hasil inpeksi bisa dilihat pada Tabel 1.

Tabel 1. Identifikasi, penilian dan penanganan risiko.

\begin{tabular}{|c|c|c|c|c|c|}
\hline \multirow{2}{*}{ Kode } & Uraian Pekerjaan & Identifikasi Bahaya & \multirow{2}{*}{$\begin{array}{l}\text { Pengendalian } \\
\text { Risiko }\end{array}$} & \multirow{2}{*}{$\begin{array}{c}\text { Penilaian } \\
\text { Risiko }\end{array}$} & \multirow{2}{*}{ Keterangan } \\
\hline & & num & & & \\
\hline 1.1 & Mobilisasi & $\begin{array}{l}\text { 1) Kecelakaan dan } \\
\text { gangguan kesehatan } \\
\text { tenaga kerja akibat } \\
\text { tenaga kurang memenuhi } \\
\text { syarat, }\end{array}$ & $\begin{array}{l}\text { 1) Menyediakan } \\
\text { kantor lapangan } \\
\text { dan tempat } \\
\text { tinggal pekerja } \\
\text { yang memenuhi } \\
\text { syarat, }\end{array}$ & 2 & $\begin{array}{l}\text { Risiko } \\
\text { Rendah }\end{array}$ \\
\hline
\end{tabular}




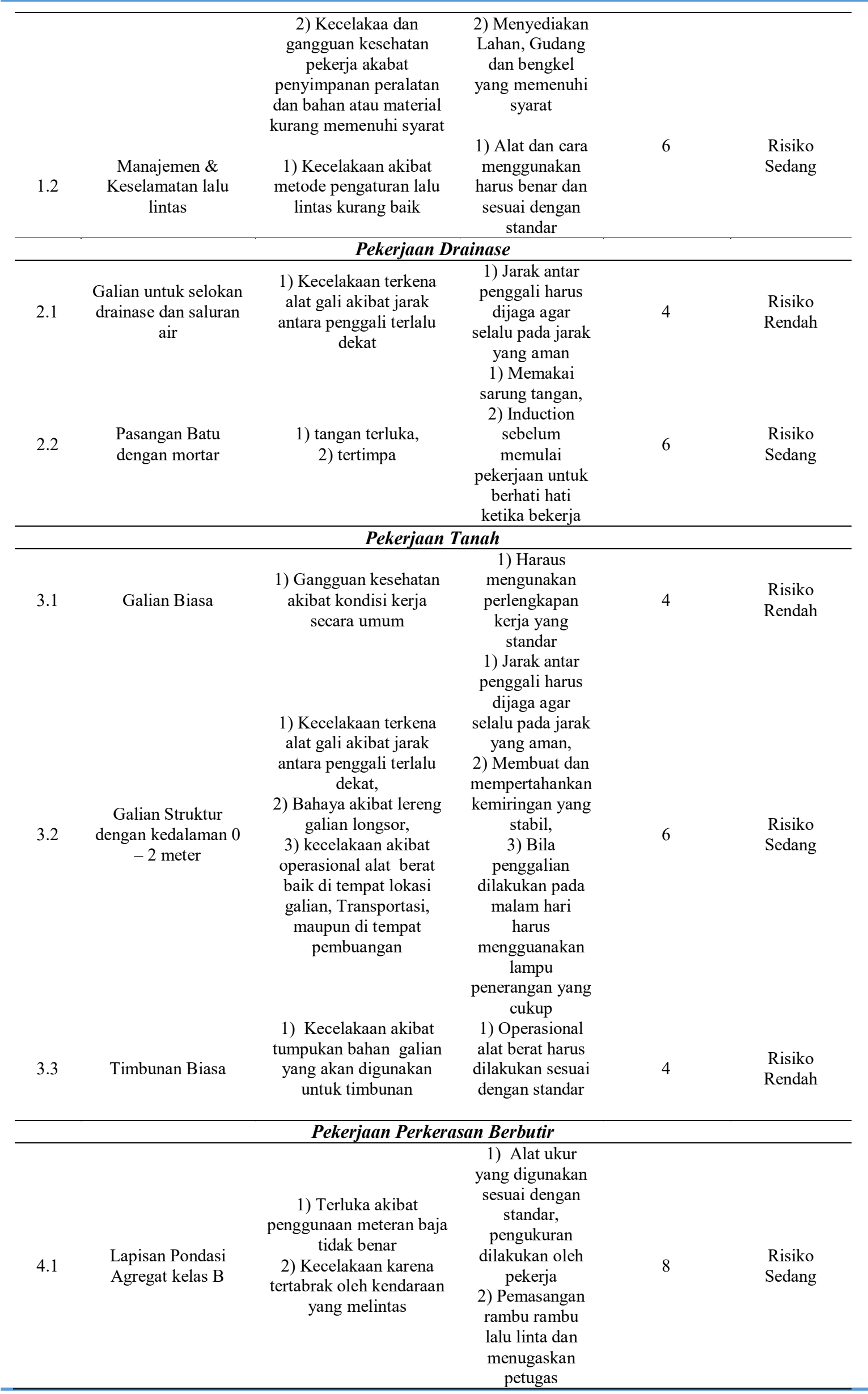




\begin{tabular}{|c|c|c|c|c|c|}
\hline 4.2 & $\begin{array}{l}\text { Lapisan Pondasi } \\
\text { Bawah (Tellford) }\end{array}$ & $\begin{array}{l}\text { 1) Terjadi kecelakaan } \\
\text { pada saat dump truck } \\
\text { menurunkan agregat } \\
\text { 2) terjadi iritasi pada } \\
\text { kulit dan paru-paru } \\
\text { akibat debu agregat yang } \\
\text { kering }\end{array}$ & $\begin{array}{c}\text { benddera lalu } \\
\text { lintas } \\
1 \text { ) } \\
\text { Pengoperasian } \\
\text { dump truck } \\
\text { harus dilakukan } \\
\text { oleh tenaga } \\
\text { trampil dan } \\
\text { pengalaman dan } \\
\text { dijaga agar tidak } \\
\text { ada orang lain } \\
\text { yang tidak } \\
\text { berkepentingan } \\
\text { berada di dekat } \\
\text { dump truk yang } \\
\text { sedang } \\
\text { menurunkan } \\
\text { agregat } \\
\text { 2) Operator } \\
\text { mesin harus } \\
\text { berpengalama } \\
\text { dan } \\
\text { pengoperasian } \\
\text { grader harus } \\
\text { dilakukan } \\
\text { dengan metode } \\
\text { yang benar }\end{array}$ & 6 & $\begin{array}{l}\text { Risiko } \\
\text { Sedang }\end{array}$ \\
\hline \multicolumn{6}{|c|}{ Pekerjaan Perkerasan Aspal } \\
\hline 5.1 & $\begin{array}{c}\text { Lapis Resap } \\
\text { Pengikat - Aspal } \\
\text { Emulsi }\end{array}$ & $\begin{array}{l}\text { 1) Terluka akibat } \\
\text { penggunaan meteran baja } \\
\text { tidak benar } \\
\text { 2) Kecelakaan karena } \\
\text { tertabrak oleh kendaraan } \\
\text { yang melintas } \\
\text { 3) terluka akibat percikan } \\
\text { aspal panas }\end{array}$ & $\begin{array}{l}\text { 1) Alat ukur } \\
\text { yang digunakan } \\
\text { sesuai dengan } \\
\text { standar, } \\
\text { pengukuran } \\
\text { dilakukan oleh } \\
\text { pekerja } \\
\text { 2) Pemasangan } \\
\text { rambu rambu } \\
\text { lalu linta dan } \\
\text { menugaskan } \\
\text { petugas bendera } \\
\text { lalu lintas } \\
\text { 3) Petugas } \\
\text { pembakaran } \\
\text { harus } \\
\text { berengalaman } \\
\text { pada bidangnya } \\
\text { dan } \\
\text { menggunakan }\end{array}$ & 8 & $\begin{array}{l}\text { Risiko } \\
\text { Sedang }\end{array}$ \\
\hline 5.2 & $\begin{array}{l}\text { Lataston Lapis Aus } \\
\text { (HRS-WC) } 3.0 \mathrm{~cm} \\
\text { (gradasi } \\
\text { senjang/semi } \\
\text { senjang) }\end{array}$ & $\begin{array}{l}\text { 1) Iritasi kulit dan paru- } \\
\text { paru } \\
\text { 2) gangguan pendengaran } \\
\text { 3) pecikan aspal panas }\end{array}$ & $\begin{array}{l}\text { APD standar } \\
\text { 1) memakai } \\
\text { APD standar } \\
\text { 2) memakai ear } \\
\text { plug atau ear } \\
\text { muff } \\
\text { 3) Petugas } \\
\text { pembakaran } \\
\text { harus } \\
\text { berengalaman } \\
\text { pada bidangnya } \\
\text { dan } \\
\text { menggunakan } \\
\text { APD standar }\end{array}$ & 6 & $\begin{array}{l}\text { Risiko } \\
\text { Sedang }\end{array}$ \\
\hline \multicolumn{6}{|c|}{ Pekerjaan Pengembalian kondisi \& Pekerjaan Minor } \\
\hline 7.1 & $\begin{array}{c}\text { Galian untuk Bahu } \\
\text { Jalan dan Pekerjaan } \\
\text { Minor Lainnya }\end{array}$ & $\begin{array}{c}\text { 1) Kecelakaan terkena } \\
\text { alat gali akibat jarak } \\
\text { antara penggali terlalu } \\
\text { dekat, }\end{array}$ & $\begin{array}{l}\text { 1) Jarak antar } \\
\text { penggali harus } \\
\text { dijaga agar }\end{array}$ & 6 & $\begin{array}{l}\text { Risiko } \\
\text { Sedang }\end{array}$ \\
\hline
\end{tabular}




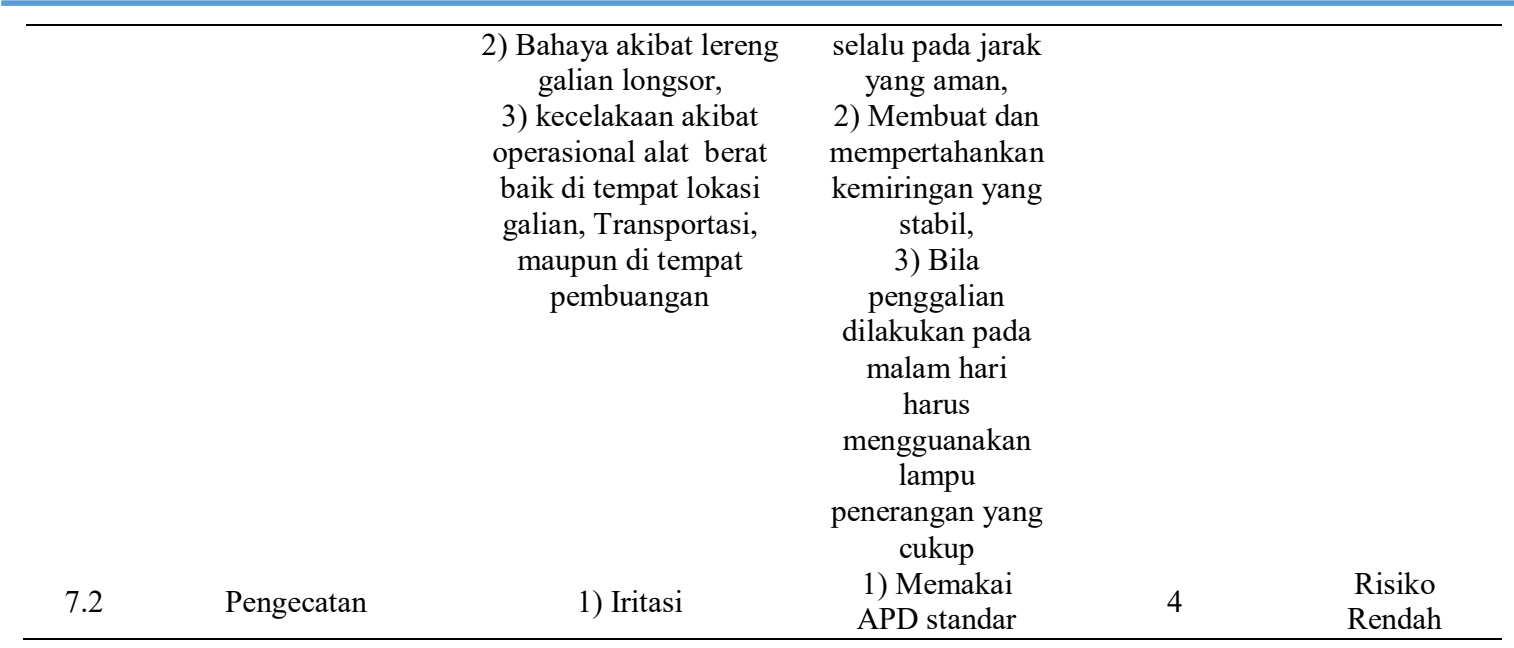

Tabel 1 tersebuit telah dilakukan proses identifikasi bahaya yang akan ditimbulkan dengan dilengkapi adanya penilaian dari setiap resiko. Sehingga dapat mempermudah penentuan kategori resiko yang terjadi seperti apa. Setelah itu, nantinya akan muncul jenis pengendalianya dan estimasi biaya dalam pemenuhan $\mathrm{K} 3$ ini.

\subsection{Perhitungan Biaya Keselamatan dan Kesehatan Kerja (K3)}

Berdasarkan hasil mitigasi risiko $\mathrm{K} 3$, dilakukan perencanaan keperluan biaya untuk mitigasi risiko mengikuti ketentuan yang ada dalam SE No. 11/SE/M/2019 [13]. Namun tidak semua ketentuan dalam surat edaran masuk kedalam perhitungan biaya K3 karena perhitungan biaya disesuaikan dengan hasil identifikasi dan penilaian risiko. Perhitungan biaya K3 didasarkan pada 2 (dua) sumber harga yaitu berdasarkan harga lapangan yang diperoleh melalui survei dan harga berdasarkan SE No. 11/SE/M/2019.

\subsection{Perhitungan Biaya K3 dengan Harga Lapangan}

Berdasarkan hasil wawancara dengan petugas $\mathrm{K} 3$ proyek. hasil perhitungan biaya $\mathrm{K} 3$ diperoleh dari RAB pekerjaan yang dapat dilihat pada Gambar 3, Gambar 4 dan Gambar 5 sebagai berikut: 


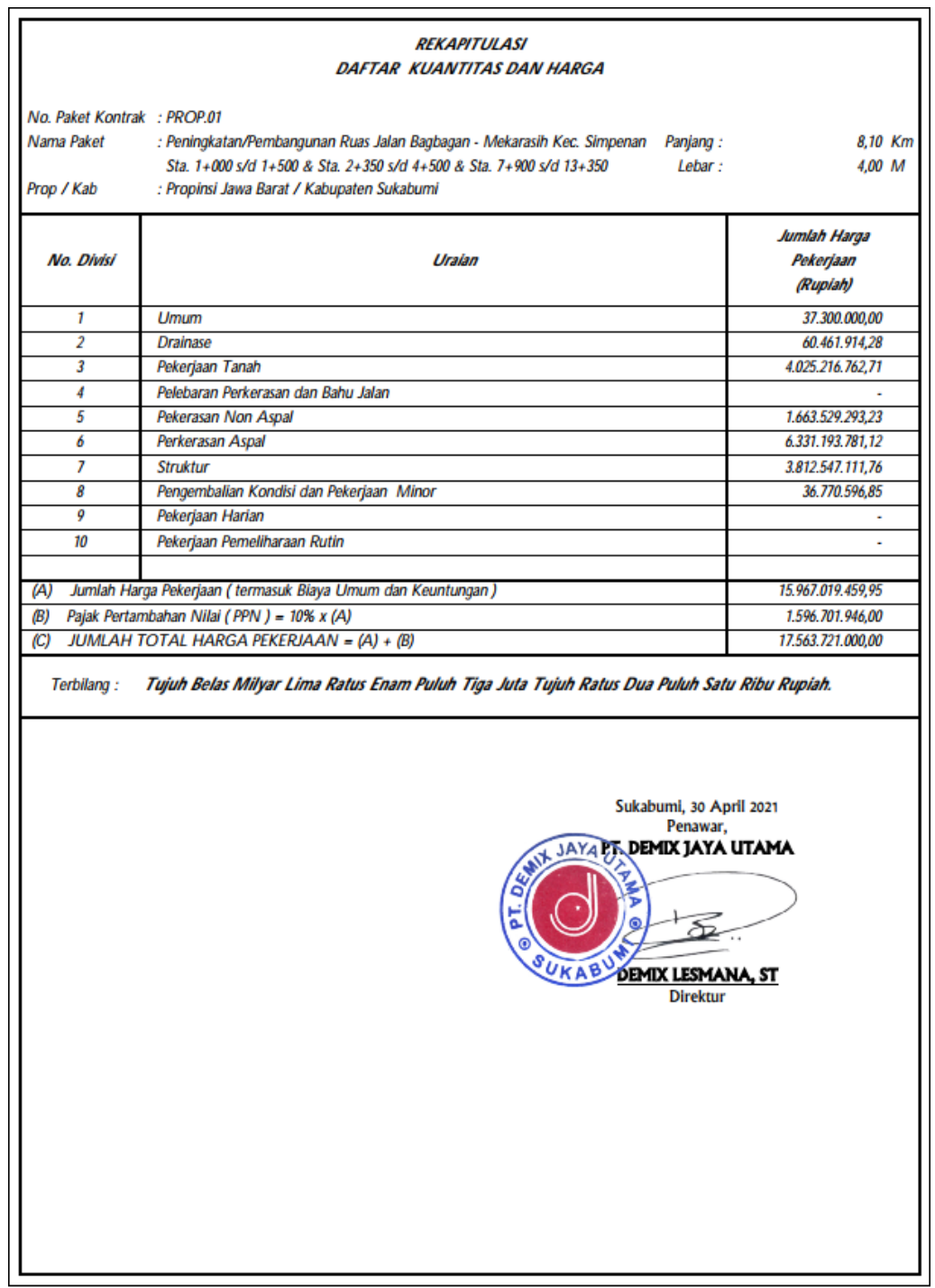

Gambar 3. Total Rencana Anggaran Biaya Perbaikan Jalan

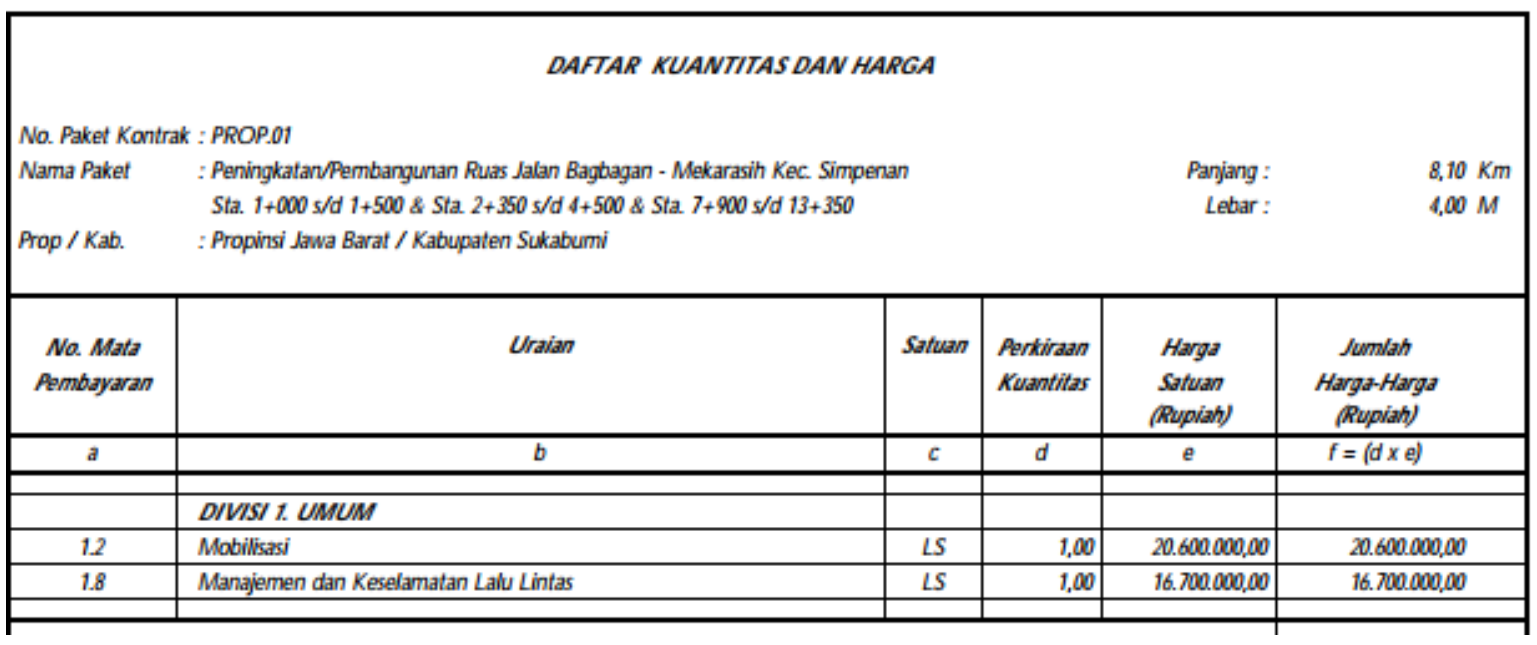

Gambar 4. Rencana Anggaran Biaya Manajemen dan Keselamaatan Lalu Lintas 


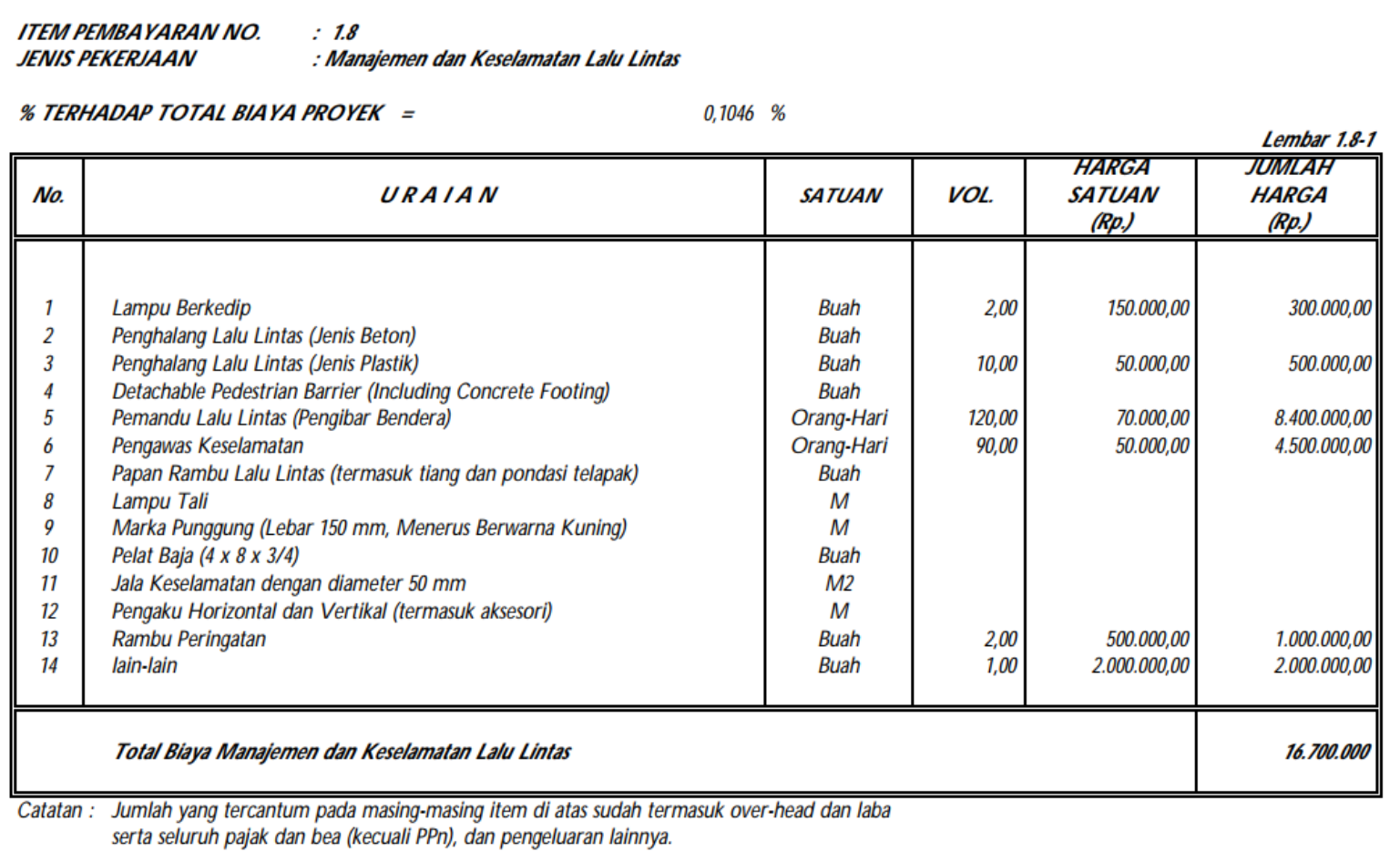

Gambar 5. Rincian Rencana Anggaran Biaya Manajemen dan Keselamatanm Lalu Lintas

\subsection{Perhitungan Biaya K3 dengan SE Nomor 11/SE/M/2019}

Berdasarkan hasil mitigasi risiko K3, dilakukan perencanaan keperluan biaya untuk mitigasi risiko mengikuti ketentuan yang ada dalam SE No. 11/SE/M/2019. Namun tidak semua ketentuan dalam surat edaran yang masuk kedalam perhitungan biaya K3 karena perhitungan biaya disesuaikan dengan hasil identifikasi dan penilaian risiko. Perhitungan biaya K3 didasarkan pada 2 (dua) sumber harga yaitu berdasarkan harga lapangan yang diperoleh melalui survei dan harga berdasarkan SE No. 11/SE/M/2019 [14]. Seperti yang terlihat pada rekap biaya K3 Tabel 2 berikut.

Tabel 2. Rencana Biaya K3 berdasarkan SE No. 11/SE/M/2019

\begin{tabular}{cc}
\hline Uraian & Total \\
\hline Penyiapan RK3K terdiri atas: & 1.250 .000 \\
Sosialisasi dan Promosi K3 terdiri dari : & 9.750 .000 \\
Alat Pelindung Kerja terdiri atas: & 15.500 .000 \\
Alat Pelindung Diri terdiri atas: & 25.700 .000 \\
Asuransi Dan Perijinan terdiri atas: & 29.000 .000 \\
Personil K3 terdiri atas: & 48.000 .000 \\
Fasilitas sarana kesehatan; & 10.000 .000 \\
Rambu-Rambu terdiri atas: & 4.800 .000 \\
Lain- Lain Terkait Pengendalian Risiko K3 & 3.610 .000 \\
Total Sistem Manajemen Keselamatan dan Kesehatan Kerja (SMK3) & 147.610 .000 \\
\hline
\end{tabular}

Rencana biaya K3 seperti yang ditunjukan pada Tabel 2 mempunyai uraian detail biaya K3. Dalam penyiapan RK3K terdiri atas pembuatan manual, prosedur, instruksi kerja, ijin kerja, dan pembuatan kartu identitas pekerja (KIP). Dalam uraian sosialisasi dan promosi K3 terdiri dari induksi K3 (safety induction), pengarahan K3 (safety briefing), pertemuan, keselamatan (safety talk dan/atau tool box meeting), pelatihan K3, simulasi K3, spanduk (banner), poster, papan informasi K3 [14]. Dalam uraian alat pelindung kerja no 3 pada Tabel 2 terdiri atas jaring pengaman (safety net), tali keselamatan (life line), penahan jatuh (safety deck), pagar pengaman (guard railling), dan pembatas area (restricted area). Dalam uraian alat pelindung kerja no 4 pada Tabel 2 terdiri atas topi pelindung (safety helmet), pelindung mata (goggles, spectacles), tameng muka (face shield), masker selam (breathing apparatus), pelindung telinga (earplug, earmuff), pelindung pernafasan dan mulut (masker), sarung tangan (safety gloves), sepatu 
keselamatan (safety shoes), untuk staf penunjang seluruh tubuh (fullbody harness), jaket pelampung (lifevest), rompi keselamatan (safetyvest), celemek (apron/coveralls), dan pelindung jatuh (fallarrester) [14].

Dalam uraian asuransi dan perijinan terdiri atas bpjs ketenagakerjaan dan kesehatan kerja surat ijin kelaikan alat, surat ijin operator, surat ijin pengesahan panitia pembina, keselamatan dan kesehatan kerja. Dalam uraian personil K3 terdiri atas ahli K3, petugas k3, petugas tanggap darurat, petugas P3K, petugas pengatur lalu lintas (flagman), dan petugas medis. Dalam uraian fasilitas sarana Kesehatan terdiri dari peralatan P3K (kotak P3K, tandu, tabung oksigen, obat luka, perban), ruang P3K (tempat tidur pasien, stetoskop, timbangan berat badan), peralatan pengasapan (fogging), obat pengasapan, dan protokol kesehatan covid [14]. Dalam uraian rambu-rambu terdiri atas rambu petunjuk, rambu larangan, rambu peringatan, rambu kewajiban, rambu informasi, rambu pekerjaan sementara, tongkat pengatur lalu lintas (warning lightsstick), kerucut lalu lintas (traffic cone), lampu putar (rotarylamp), lampu selang lalu lintas. Dalam uraian lain- lain terkait pengendalian risiko $\mathrm{K} 3$ terdiri dari alat pemadam api ringan (apar), sirine, bendera $\mathrm{k} 3$, jalur evakuasi (escape route), lampu darurat (emergency lamp), program inspeksi dan audit internal, pelaporan dan penyelidikan insiden [14].

\subsection{Perbandingan Biaya $\mathrm{K} 3$ dengan nilai kontrak}

Hasil perhitungan biaya K3 berdasarkan harga lapangan dan SE Nomor 11/SE/M/2019, selanjutnya dilakukan perbandingan persentase biaya-biaya tersebut dengan nilai kontrak proyek. Nilai kontrak yang dipakai adalah nilai kontrak tanpa PPN (Pajak Penambahan Nilai) 10\%. Adapun hasil perhitungan ditunjukkan dalam Tabel 3 berikut [14].

Tabel 3. Perbandingan Biaya K3 Pada Proyek dan . K3 SE No 11 SE/M/2019

\begin{tabular}{ccc}
\hline Uraian Biaya K3 & Jumlah Harga (Rp.) & \% \\
\hline RAB tanpa PPN 10\% & $15.967 .019 .495,00$ & 0,10 \\
Biaya K3 di lapangan & $16.700 .000,00$ & 0,10 \\
Biaya K3 SE No 11 SE/M/2019 & $146.710 .000,00$ & 0,91 \\
\hline
\end{tabular}

Berdasarakan hasil analisa perbandingan dan persantase biaya K3, dapat dilihat dalam Tabel 3 bahwa persentasse biaya K3 dilapangan lebih sedikit dibandingkan persantase biaya K3 harga SE No. 11/SE/M/2019 dengan selisih 0,81 \% dimana hal ini disebabkan oleh karena item SMK3 yang tercantum dalam SE No. 11/SE/M/2019 yang perlu diterapkan sesuai dengan ketentuan seperti penyiapan RK3K, sosialisasi, dambu-rambu dan lain sebagainya, sedangkan dalam RAB pekerjaan tidak tercantum, sehingga penerapan SMK3 dalam proyek tidak terlaksana dengan optimal karena tidak ada kesesuaian antara RAB proyek dengan ketentuan SE No. 11/SE/M/2019. Namun demikian pelaksanaan proyek berjalan tanpa terjadi kecelakaan selama proyek berjalan.

\section{Kesimpulan}

Biaya K3 yang diperlukan dalam proyek peningkatan ruas jalan Bagbagan- Mekarasih kecamatan Simpenan menurut RAB adalah Rp. 16.700.000,00 atau hanya senilai $(0,10 \%)$ yang mengacu dalam Manajemen dan Keselamatan Lalu lintas dari total anggaran Rp. 15.967.019.495,00. Sedangkan biaya K3 berdasarkan peraturan SE No.11/SE/M/2019 adalah Rp. 146.710.000,00 (0,91\%). Selisih biaya ini disebabkan oleh karena item SMK3 yang tercantum dalam SE No. 11/SE/M/2019 seperti penyiapan RK3K, sosialisasi, rambu-rambu, alat pelindung kerja, alat pelindung diri, asuransi dan perijinan, personil k3 konstruksi, fasilitas, sarana, prasarana, alat kesehatan, konsultasi ahli tidak secara keseluruhan tercantum dalam dalam RAB proyek. Biaya $\mathrm{K} 3$ dalam RAB proyek banyak item yang tidak tercantum seperti alat pelindung diri, fasilitas sarana kesehatan dan yang lain sebagainya. Penelitian ini menemukan ketidak seimbangan mengenai biaya $\mathrm{K} 3$ antara pelaksanaan dalam proyek dengan ketentuan yang berlaku, oleh karena itu untuk dimasa yang akan datang penyelenggara proyek perlu lebih spesifik merencanakan biaya K3 agar sesuai dengan kebutuhan dalam proyek. Saran dari penelitian ini penyedia jasa konstruksi seharusnya menyediakan biaya untuk keperluan K3 yang diambil dari total biaya proyek meskipun biaya tersebut masuk kategori biaya umum dan tidak spesifik untuk biaya $\mathrm{K} 3$ yang tercantum dalam kontrak. 


\section{Daftar Pstaka}

[1] N. Fadillah, "Gambaran Perilaku Tenaga Kerja dan Pelaksanaan Program Kesehatan dan Keselamatan Kerja (K3) Konstruksi dalam Pembangunan Balai Diklat BPK-RI Makassar oleh PT. Wijaya Karya (Persero) Tbk." Universitas Islam Negeri Alauddin Makassar, 2015. Available at: Google Scholar.

[2] T. D. Rawis, J. Tjakra, and T. T. Arsjad, "Perencanaan biaya Keselamatan dan Kesehatan Kerja (K3) pada proyek konstruksi bangunan (studi kasus: sekolah st. ursula kotamobagu)," J. Sipil Statik, vol. 4, no. 4, 2016. Available at: Google Scholar.

[3] Z. M. EQ, "Pengaruh Program Keselamatan Dan Kesehatan Kerja, Sistem Pengawasan Kerja dan Lingkungan Kerja terhadap Potensi Kecelakaan Kerja Karyawan Studi pada PT. Aneka Dharma Persada (PT. ADP) Kecamatan Bantul Kota Yogyakarta," 2020. Available at: Google Scholar.

[4] Paikun, S. Rahayu, A. Selpi, A. Awalia, and Jasmanyah, "Quick Ways to Calculate Shophouse Construction Project Materials Using Regression Analysis Program," 5th Int. Conf. Comput. Eng. Des. ICCED 2019, pp. 4-9, 2019, doi: 10.1109/ICCED46541.2019.9161083.

[5] R. Gunawan, "Perencanaan biaya keselamatan dan kesehatan kerja (K3) pada proyek irigasi." Available at: Google Scholar.

[6] M. F. Romadhon, "Persentase biaya K3 pembangunan saluran drainase." Available at: Google Scholar.

[7] C. V. M. Utama, "Perhitungan Biaya Sistem Manajemen Keselamatan dan Kesehatan Kerja (SMK3) pada Struktur Bangunan Atas Proyek Hotel Swiss-Belinn Juanda." Institut Teknologi Sepuluh Nopember, 2017. Available at: Google Scholar.

[8] F. C. S. Adiyanta, "Hukum dan Studi Penelitian Empiris: Penggunaan Metode Survey sebagai Instrumen Penelitian Hukum Empiris," Adm. Law Gov. J., vol. 2, no. 4, pp. 697-709, 2019. doi: 10.14710/alj.v2i4.697-709

[9] N. P. I. Yuliana and N. K. S. E. Yuni, "Analisis anggaran biaya keselamatan dan kesehatan kerja proyek konstruksi gedung SMA N 2 Abiansemal," Padur. J. Tek. Sipil Univ. Warmadewa, vol. 9, no. 2, pp. 201-211, 2020. doi: 10.22225/pd.9.2.1792.201-211

[10] E. Widowati and S. R. Rahayu, "Penggunaan Job Hazard Analysis dalam Identifikasi Risiko Keselamatan Kerja pada Pengrajin Logam," HIGEIA (Journal Public Heal. Res. Dev., vol. 2, no. 4, pp. 510-519, 2018. doi: 10.15294/higeia.v2i4.23564

[11] F. Fassa, Pengantar Keselamatan Dan Kesehatan Kerja Konstruksi. Podomoro University Press, 2020. Available at: Google Scholar.

[12] C. Yuliana, "Manajemen Risiko Kontrak Untuk Proyek Konstruksi," Rekayasa Sipil, vol. 11, no. 1, pp. 9-16, 2017. doi: 10.21776/ub.rekayasasipil.2017.011.01.2

[13] A. C. Kusumawati and N. Martina, "Analisis biaya pengendalian risiko K3 pada pekerjaan pemeliharaan jalan tol berdasarkan Permen PU No 07/PRT/M/2019 dan SE Menteri PUPR No 11/SE/M/2019," in Prosiding Seminar Nasional Teknik Sipil, 2019, vol. 1, no. 1, pp. 720-728. Available at: Google Scholar.

[14] A. Umum, "Surat edaran nomor: 11/SE/M/2019 tentang petunjuk teknis biaya penyelenggaraan sistem manajemen keselamatan konstruksi," 2019. Available at: Google Scholar. 